DOI: $10.15503 /$ jecs20152.5.8

\title{
PREFACE: SCIENCE BETWEEN AND AGAINST DISCIPLINES IN THE SOCIAL SCIENCES AND HUMANITIES
}

\author{
Aleksander KobylareK \\ University of Wroclaw \\ E-mail: alelsander.kobylarek@gmail.com
}

\begin{abstract}
The article describes the role of interdisciplinarity in the process of making science. Two patterns of research and development of discipline are presented: the closed pattern which concentrates on specialization and the open pattern which fosters interdisciplinary science. The key to success is always openness for new scientific experiences and communities. The conclusion of the article is a proposal for finding new scientific communities, which could be interested in new ideas, research and thoughts where interdisciplinary analyses are not acceptable to the local scientific community.

Keywords: interdisciplinarity, Humboldt, university, science, specialization, academy, feudalism, ignorance
\end{abstract}

Modern science is divided into disciplines which are very specialized. This situation is an effect of two developmental leaps. The first one, from the end of the $19^{\text {th }}$ century, started the age of fast technical progress. In the second one, about 50 years later, it was already very easy to define the increase of knowledge as a geometric progression. Up to the $19^{\text {th }}$ century one person would be able to master the whole of human scientific achievement. Nowadays no one would even think to study all the scientific disciplines. Science in every discipline seems to be so huge and incredible that studying all of its disciplines would be impossible.

The increasing of science about the world and human beings does not mean that we humans are automatically satisfied with effects of the research. Although we know more about the world and humankind, the important real problems have still not all been resolved. Small scale scientific achievements are not enough to allow us to feel comfortable and safe. Living in a hi-tech world people don't even think about the fact, how many rules, research and scientific achievements are necessary for every day gadgets?

In the $20^{\text {th }}$ century the sceptical attitude towards science became more and more prevalent. After many ideological revolutions in the scientific world and paradigmatic changes, scientists and researchers have started to rethink the real value of science. Nowadays we have actually two different views of science. We are delighted by the possibilities of using the achievements of engineering and 
technology: the effects of the development of such disciplines as mathematics, physics, chemistry or biology. At the same time we are disappointed with the weakness of 'strong' theories about humanity and our social world.

The weakness of humanities insists in the multitude of theories and in the permanent incertitude or doubt as to which theory fits for the correct explanation of the specific situation. In such cases there is a problem in recognizing which of the theories could be adopted in the process of resolving of a practical problem of a human being. Paradoxically the more theories we have produced in social sciences and humanities, the less certain we are about humanity and the social facts surrounding it.

At the same time the $20^{\text {th }}$ century turned science into a massive product. There are many people engaged in the process of doing research, publishing, spreading information about results and hardware as well. In science mass production means the working of large teams on very specific, detailed technical problems. Small effects can be tested immediately. In social sciences and humanities the effects are more elusive and can very rarely be tested at all. For some of the researchers it is a reason to abandon qualitative methods of research and to concentrate on countable indicators. For humanistic orientated scientists such a restricted approach does not make sense and they... paradoxically restrict their research to qualitative methods. It leads to the situation, in which methodological schools are fighting for the only truth, supposing that the method is the key for success in explanation of the (post)modern world. In many cases members of a methodological school do not understand and do not accept the point of view of the other researchers and cooperate only with the researchers who represent the same methodological approach.

Unfortunately the methods are only one aspect of the problem referred to as separation of the disciplines. Other obstacles are:

- ignorance or even being unacquainted with the science at all,

- aversion and contempt towards other scientific schools,

- belief in the infallibility of their own approach to the researched reality, or

- fear of mistakes and for the exposure of personal scientific ignorance.

All these factors are strictly related to feelings and beliefs. That approach should be seen as contrary to scientific thought, a kind of sin against professionalism of research, openness for criticism, objectivism and communication, which are the essence and the existence of science. For scientists, who are operating 'professionally' with fears and beliefs, the core of the science is not important.

In such cases articles and conferences are the tools for spreading ideologies and paradigms. The mentioned pseudo- scientists usually employ very complicated syntax and a lot of difficult 'scientific' words. In their opinion the complicated and generally unintelligible language is evidence of the scientific dimension of the statement. The truth is that this kind of communication is... hard to understand and complicated and nothing more. The scientific value of information does not insist in producing science as an exclusive phenomenon, impossible for a mere mortal to understand, but something nearer the opposite and something more substantial.

Scientists who want to make people-friendly science should take into consideration some simple facts about the content, form and aim of the scientific communication. 
Most important is definition of the recipient and customer of the scientific content. If we are planning that our recipients will be only other scientists / specialists in the same subject, we can arrange for the the article or paper to be informative and 'technical' as much as possible. But it means that the information will be meaningful to only a few people, those who are the most interested in the presented topic. Others will be not interested in such science at all and it means that the power of newly published articles and conferences will be restricted only to the some specialists, who will develop the topic in the future... or not. Communication in plain language permits the theories and rules to be understandable by everyone, who can then use the new science in life. It means that the form always depends on the perceived recipients. In humanities and social sciences the wider audience seems to be apropriate as the recipient for the theories and hypotheses.

Many other factors are important in making science. For example the theories should be new, the hypothesis- interesting, the research- important. For newcomers everything could be interesting and there is no problem with the choice of the topic for the research (of course it does not mean that the new topic for the young researcher automatically means something new in science for everybody else). After many years when the beginners become experienced researchers, the interested topic of research is not so interesting anymore. There comes the need for a change of scientific interests. Unfortunately some of the scientific communities are convinced that the best scientist should be highly specialized. I have noticed many times the tragedy of young scientists, who have become tired and bored with the same topic pursued for years.

The observation and analysis of any development or curriculum of the researchers from the scientific communities which I know, leads me to to a very important conclusion. In humanities and social sciences, specialization could be the reason for intellectual and scientific development only for a few years. After that a scientist should find new scientific interests and new topics for research. Everlasting specialization means degeneration of thoughts, intellectual collapse and auto-plagiarism.

For scientists who are interested in totally new topics of research trans-disciplinarity is a way of finding new ideas and research interests. It is not the only reason for trying new disciplines. The most interesting and very important problems are very often between scientific disciplines. It means they are worth resolving (instead of the old, well researched fields of science).

Research between disciplines is more difficult and it needs more intellectual preparation of the researchers. There is one big thread, which every multidisciplinary researcher has to face. The most dangerous situation for the young multidisciplinary scientist is when he/she has to face the opinion of the community in which nobody understands the rules of another scientific discipline. The mentioned situation is an example of the weak or even degenerated scientific community, which is closed inside its closed Ivory Tower but I think that it is not rare in the postHumboldtian university in Europe. In such institutes and departments nobody has enough scientific value and intellectual power to judge any of the interdisciplinary pieces of work. The negative opinions and reviews are the natural consequence of 
ignorance of the reviewers, who are not able to make a right evaluation of an interdisciplinary paper. The ignorance and fears of the decision- makers are killing-off the most interesting scientific interdisciplinary talents and for them very often this is the reason for abandoning the world of science. It means that very often the weakness and injustice of the scientific community is the first and most important reason for loss and decline of the most attractive scientific talents.

We are not able to convince such communities about these refreshing the ideas because the communities are closed. Professors and decision- makers who rule scientifically weak institutes are not able to listen other opinions because they are already convinced about their infallibility and that everyone outside their community must be wrong in their opinion. The depreciation of the opponent is the reason for refusing any kind of dialogue.

How can we find the solution for the problem of the weak scientific community? The only way is to publish outside it. The way to be better in making science is finding open minded international communities of researchers, who are specialists in interesting topics. The openness of the scientific community should be the most important factor to look for. On the other hand the young open minded scientists, who are able to do interdisciplinary research should be very interesting for the scientific communities, because they are able to introduce new ideas and thoughts. And without fresh research every scientific community will stay closed, stiff and finally degenerate.

Multi-disciplinary studies and research are more interesting and they make science more attractive for young researchers. There is no serious reason to restrict research to the just one discipline. The ignorance and intellectual weakness of the local scientific community cannot be an excuse and the young researchers staying in the non-developmental team could be at least as good as the best scientists from... the closed local scientific community. Local science may be enough for those within it and with little significance in the wider scientific community and for people without ambitions.However, if these young talents would like to make real science, develop methods of research and finally say something important about reality, they are obliged to do everything to reach the wider scientific community and publish in the best forward-looking international journals. 